\title{
Thoracic spine type $C$ injuries: injury profile, management and outcome
}

\author{
Gheorghe Checiu, Cristian Filip, Daniel Serban, Niki Adrian \\ Calina, Marius Podea, Costica Zamfir, Florin Exergian
}

"Bagdasar-Arseni” Clinical Emergency Hospital, Spine Surgery, Bucharest

In the last years we observed an increased number of patients with multiple lesions after high energy accidents. Type $\mathrm{C}$ injuries of the thoracic spine are the most severe lesions, with the worse prognosis. The study analyzes the injury profile, management and outcome of all patients with thoracic spine, from T1- to T10, type C injuries treated in the Spinal Surgery Department of "Bagdsar- Arseni" Emergency Hospital, in the last 5 years. There were 26 patients admitted in the study, mostly male, $77 \%$, with a mean age of 33.8 years. All of them were victims of high energy accidents, and all had spine injury associated with multiple lesions (head, thoracic, abdominal and limbs). We have chosen a posterior approach in all cases, with laminectomy or hemilaminectomy, permitting us to achieve all the major objectives of surgery, with the advantage of lower blood loss and a reduced operating time. The purpose of surgery was to achieve decompression of the spinal cord and stability of the thoracic spine. We treated 19 patient surgically and 4 patient conservative. Thoracic spine type $\mathrm{C}$ fractures remain a challenge for the spinal surgeon. These lesions require a multidisciplinary team approach for the treatment of associated lesions. The main goal of surgery is to achieve stability of the fractured segments. The timing for surgery is indicated mainly by associated respiratory problems. Key words: thoracic, fracture, type $\mathrm{C}, \mathrm{AO}$ classification.

\section{Introduction}

With an increasing number of car accident each year and a reorientation of the population's recreational activities we observed an increased number of patients presenting with spine fractures resulting from high energy accidents. This study analyzes thoracic fractures type $\mathrm{C}$, according to $\mathrm{AO}$ classification described by Magerl and Aebi in 1994. On the basis of this classification, type C lesions are the most severe fractures of thoracic and lumbar spine and, in the majority of cases are associated with neurologic disorders caused by spinal cord compression. The characteristics of this type of fracture are represented by anterior and posterior column 
injuries with associated rotation and translation of vertebral bodies, with rupture of all ligamentous structures including intervertebral discs, fractures of articular processes, transverse processes with costal dislocation or rib fractures affecting the proximal third of the rib. Type $\mathrm{C}$ fractures are subdivided into 3 categories: C1, represented by type $\mathrm{A}$ fractures with rotational force associated, $\mathrm{C} 2$, type $\mathrm{B}$ fractures with rotational force associated and $\mathrm{C} 3$, represented by purely rotational injuries. $(1,2)$

The study included all patients that were admitted in the Department of Spine Surgery of "Bagdasar-Arseni" Emergency Hospital with thoracic, from $\mathrm{T} 1$ to $\mathrm{T} 10$, type $\mathrm{C}$ fractures between January 2009 and August 2014. There were 26 patients admitted, with a mean age of 33.8 years, mostly male. All of these patients were victims of high energy accidents, mostly car and motorcicle accidents.

Because of the complexity of the $\mathrm{AO}$ classification its daily use is questionable, but, although there are newer classification methods, the AO classification is still used to determine the prognosis of patients and the choice of the most appropriate treatment.

\section{Epidemiological data}

Spine fractures represent approximately $6 \%$ of all fractures worldwide. The most affected segments of the spine are the thoracic and lumbar spine, with an incidence of 700000 cases per year.

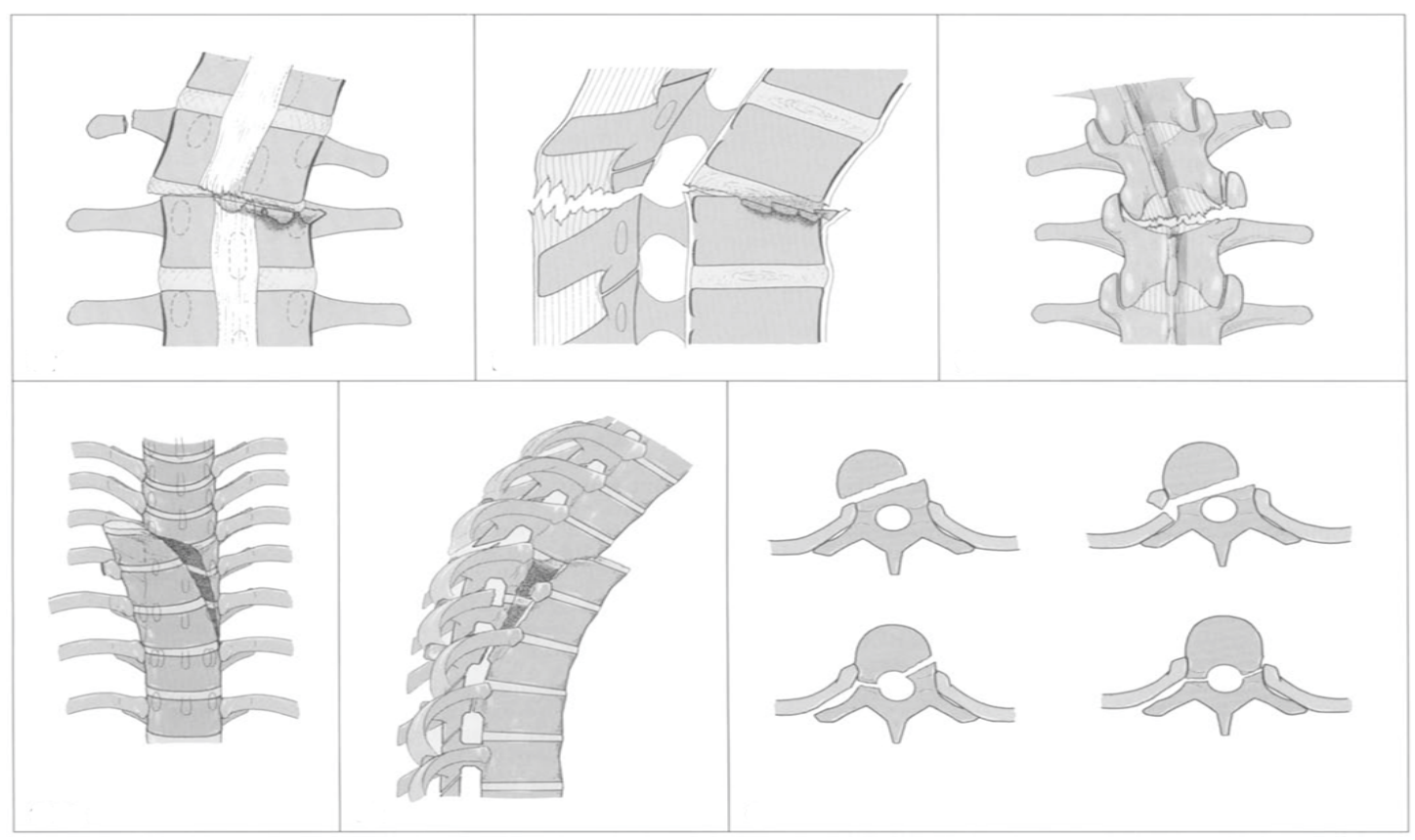

Figure 1 - Characteristics of type $\mathrm{C}$ fractures according to AO classification. (Magerl F, Aebi M, Gertzbein SD, Harms J, Nazarian S (1994) A comprehensive classification of thoracic and lumbar injuries) 
DOI: 10.2478/romneu-2014-0058

Approximately $50 \%$ of these fractures are situated at the thoracolumbar junction, $32 \%$ in the lumbar spine and $16 \%$ in the thoracic spine [1]. Thoracic type $\mathrm{C}$ lesions represent $35.8 \%$ of all fractures situated in the thoracic spine [2].

There were 26 patients included with a mean age of 33.8 years. We observed a high incidence of type $\mathrm{C}$ thoracic fractures in young patients, $65 \%$ being between 20 and 40 years old. The main cause of injury was represented by car accidents in $46 \%$ of cases, followed by fall from heights in $38.5 \%$ of cases and motorcycle accidents in $11.5 \%$ of cases.

Comparing them to fractures of the lumbar spine or thoracolumbar junction which associate neurological impairment in $25.7 \%$, respectively $23 \%$ of cases, thoracic spine fractures have a higher incidence of neurological disorders, $38.6 \%$ of patients presenting neurological impairment. Thoracic type $\mathrm{C}$ fractures associate neurological deficits in $57.7 \%$ of cases, opposed to $16.6 \%$ in type A fractures and $35 \%$ in type B fractures. The highest percent of complete neurological lesions described in literature are also thoracic type C lesions, in $38.5 \%$ of cases [3].

The most common site of fracture in our study was $\mathrm{T} 7-\mathrm{T} 8$, in $23.3 \%$ of cases, followed by T9-T10, in $20 \%$ of cases and then T4-T5 and T5-T6 in 16.6\% of cases each.

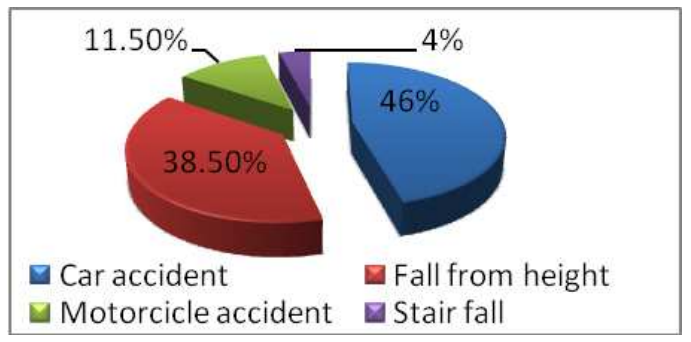

Figure 2 - Main cause of injury of patients with thoracic type $\mathrm{C}$ fractures
TABLE I

Site of fracture of patients with thoracic type C lesions

\begin{tabular}{|l|l|}
\hline FRACTURE SITE & PERCENT OF PATIENTS \\
\hline T1-T2 & $0 \%$ \\
\hline T2-T3 & $0 \%$ \\
\hline T3-T4 & $10 \%$ \\
\hline T4-T5 & $16.60 \%$ \\
\hline T5-T6 & $16.60 \%$ \\
\hline T6-T7 & $3.30 \%$ \\
\hline T7-T8 & $23.30 \%$ \\
\hline T8-T9 & $10 \%$ \\
\hline T9-T10 & $20 \%$ \\
\hline
\end{tabular}

\section{Patients and methods}

The article represents a retrospective study that includes all patients treated in our department in the last 5 years. There were 20 males and 6 females, $65 \%$ of patients being between 20 and 40 years old.

Despite literature data, the majority of patients admitted presented complete neurologic lesions, graded Frankel A. 21 out of 26 patients included were Frankel A, 3 patients were Frankel C and 2 patients were Frankel D.

The most frequent level of injury was T4, in $23 \%$ of cases, followed by T7 in $19.2 \%$ of cases and then $\mathrm{T} 8$ in $15.4 \%$ of cases.

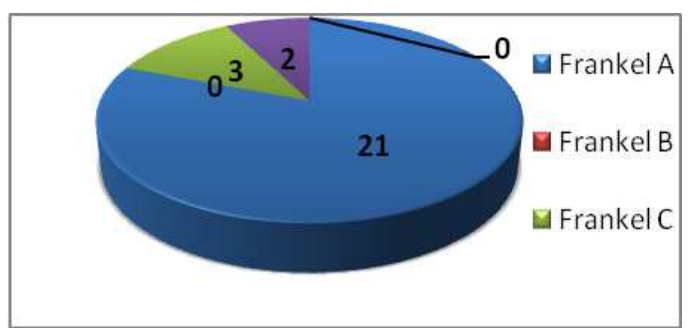

Figure 3 - Neurologic status of admitted patients 
Table II

Neurologic level of injury of admitted patients

\begin{tabular}{|l|l|}
\hline NEUROLOGIC LEVEL & $\begin{array}{l}\text { PERCENT OF } \\
\text { PATIENTS }\end{array}$ \\
\hline T1 & $0 \%$ \\
\hline T2 & $0 \%$ \\
\hline T3 & $7.70 \%$ \\
\hline T4 & $23 \%$ \\
\hline T5 & $11.50 \%$ \\
\hline T6 & $11.50 \%$ \\
\hline T7 & $19.20 \%$ \\
\hline T8 & $15.40 \%$ \\
\hline T9 & $11.50 \%$ \\
\hline T10 & $0 \%$ \\
\hline
\end{tabular}

One of the main problem of these patients is represented by associated complications, mainly pulmonary lesions. Literature studies demonstrate a proportional relation between the type of spinal injury according to $\mathrm{AO}$ classification and associated lesions, $42 \%$ of patients with type A fractures presenting associated lesions, $62 \%$ in type B fractures and $66 \%$ in type $\mathrm{C}$ fractures (2).

All patients included in the study presented with associated lesions, $100 \%$ of patients presented associated thoracoabdominal trauma, $88.5 \%$ traumatic brain injury and $42 \%$ presented with associated limb or pelvic fractures.

Out of the 26 patients, $69 \%$ associated mild traumatic brain injury, $8 \%$ moderate traumatic brain injury, $11.5 \%$ severe brain injury and $11.5 \%$ had no head injury.

The main problem for this patients was represented by thoracoabdominal trauma, patients presenting in a severe state, the majority in respiratory insufficiency which delayed the moment of surgery until they were stable from a respiratory and cardiac point of view. Thoracoabdominal trauma was associated in $100 \%$ of cases. $69 \%$ of patients presented with respiratory insufficiency which was caused by haemothorax, pneumothorax, rib fractures or pulmonary contusions. $92 \%$ of patients presented haemothorax, 15 patients with bilateral haemothorax and 9 patients with unilateral haemothorax. $23 \%$ of patients presented pneumothorax. Out of this patients, a pleural drainage system was required in 69\% of cases and was maintained for an average duration of 10 days. $50 \%$ of patients presented with rib fractures.

Thoracoabdominal associated trauma represented a major complication that dictated the moment of surgery. Patients were scheduled for surgery when associated respiratory complications were resolved, meaning, patient could breathe on his own, without respiratory support, with an oxygen blood saturation over $90 \%$ and pulmonary Xray or chest $\mathrm{CT}$ with little or no modifications.

Also $11.5 \%$ of patients associated spleen rupture which needed emergency surgical intervention.

11 patients presented limbs or pelvic fractures. $30.5 \%$ of admitted patients presented superior limbs fractures, $11.5 \%$ inferior limbs fractures and only $3.8 \%$ presented with pelvis fractures.

The high percentage of patients with multiple lesions is a statement that sustains the severity of this lesions and the high energy accidents that produced them. Also, it implies that the patient needs a multidisciplinary team approach. 
DOI: 10.2478/romneu-2014-0058

Table III

Associated thoracoabdominal trauma

\begin{tabular}{|l|c|}
\hline ASSOCIATED THORACOABDOMINAL TRAUMA \\
\hline Respiratory insufficiency & $69 \%$ \\
\hline Haemothorax & $92 \%$ \\
\hline Pneumothorax & $23 \%$ \\
\hline Rib fractures & $50 \%$ \\
\hline Spleen rupture & $11.5 \%$ \\
\hline
\end{tabular}

Other rare complications included: decubitus lesions, pneumonia, pneumomediastine, superior digestive hemorrhage, pulmonary thromboembolism, urinary tract infections, diarrhea syndrome, transverse colon rupture, hepatic injury, azygos vein injury, burn injuries after electrocution, radial nerve palsy, brachial plexus elongation, stern fractures and amputated fingers.

\section{Treatment}

There are two main types of treatment for spine fractures, surgical treatment and conservative treatment. The method of treatment is chosen on the following criteria: the instability grade of the fracture, neurological status and the impossibility of maintaining an external immobilization device for different reasons (5).

In the vast majority of cases type $\mathrm{C}$ fractures of the thoracic spine are treated surgically because of their instability and associated neurological deficits. $(1,2,3)$

Out of the 26 patients admitted, 19 patients were operated, 4 were treated conservative, 2 patients died before surgical intervention an 1 patient was transferred to another clinic at will.

\section{Conservative treatment}

We choose conservative treatment in 4 cases on the following criteria:

1) Patients with complete neurological lesions, graded Frankel A

2) Fractures of the upper thoracic spine, a segment that need to sustain less axial pressure then the lower thoracic spine

3) Multiple comorbidities associated

4) A high risk of surgical treatment

The fractured vertebrae were T5-T6 for 2 patients, T4-T5 for one case and T8-T9 in another case. All patients presented complete or partial consolidation of the fracture at 2 months follow-up, and could sit in a wheel chair. There was no neurological improvement in any of these cases.

\section{Surgical treatment}

$73 \%$ of patients underwent surgery for thoracic spine type $C$ fractures. In all cases we chose a posterior approach with laminectomy in $63 \%$ of cases and hemilaminectomy in $37 \%$ of cases.

There are different methods of approach described in literature, posterior, anterior or combined approaches. The most common approach is posterior, achieving all the major objectives of surgical treatment with lower blood loss and a smaller duration of surgery. Operating time can extend up to $100 \%$ in combined approaches and up to $25 \%$ in anterior approaches. Radiation exposure is also higher in case of a combined approach (3).

The major objectives of surgical treatment were decompression of the spinal cord and spine fusion using metallic implants and bone graft fusion. It was observed that a reduction of the spinal canal increases the risk of 
neurological impairment 3.5 times comparing them with patient without reduction of the spinal canal. Comparing with other segments of the spine, the thoracic spine has the highest rate of neurological impairment in case of spinal cord compression, $51.4 \%$ of patients presenting with neurological deficits, compared to $36.2 \%$ at the thoracolumbar junction and $30.6 \%$ in the lumbar spine. The reduction limit of the thoracic spinal canal before neurological deficits appear is $10 \%$. All objectives of surgical treatment were achieved through a posterior approach. There was no need for an anterior or a combined approach.

The timing of surgical treatment is an important problem for patients with thoracic type C fractures. Normally, the prognosis is better if an early surgical intervention with decompression and fusion of the spine is done. Unfortunately, early surgical treatment is not always possible, patients presenting with an altered general condition and multiple lesions associated (6) .Literature articles sustain that white matter has a much higher resistance than grey matter, lesions of white matter being reversible even after 72 hours while grey matter lesions are instantly irreversible (7). Animal studies returned good results for early decompression, in the first 8 hours after trauma $(8,9)$. This remains a controversial problem. Burk, Berryman (10) and Hadley with associates (11) describe in a retrospective study that the moment of decompression for cervical spine lesions is more important for neurologic recovery than the method of decompression. On the other hand, Vacaro and associates (12) published a prospective randomized study for cervical spine lesions and demonstrated that there is no neurological advantage associated with early decompression. Another recent prospective study for lesions of the thoracic spine demonstrated an insignificant tendency of neurologic improvement associated with early decompression (13).

Weather early surgical intervention has an advantage on neurological improvement is unclear, although it is certain that surgical intervention in less than 72 hours reduces the average stay in ICU, respiratory complications, morbidity and mortality (14, 15). In a revision of literature done by Bellabarba and associates early surgical intervention is associated with a shorter ICU stay and a shorter hospital stay (16).

There are also studies sustaining that early fusion in this type of lesions associate reduced pulmonary complications, a reduced time of necessary mechanical ventilation hours and decreases the incidence of pneumonia. This favorable effects are clearer in case of thoracic spine fractures $(17,18,19,20,21,22,23,24)$. The obvious thought was that mortality is higher in case of early surgical intervention, but, a study on 871 patients who were split in 2 groups depending on the moment of surgery returned no differences (22). Studies also revealed smaller costs associated with early surgical treatment $(25,17,22)$.

The timing of surgical treatment in our study was dictated primarily by pulmonary complications. The average time until surgery was 14 days, with a minimum time of 6 days and a maximum of 85 days. The average duration of surgery was 252 minutes and the average blood loss was $463 \mathrm{ml}$, with a 
DOI: 10.2478/romneu-2014-0058

minimum value of $200 \mathrm{ml}$ and a maximum of $1000 \mathrm{ml}$.

One of the most important objectives of surgical treatment was to achieve stability of the spine. In the majority of cases stability was achieved through a metallic fusion, with transpedicular screws and rods associated with autologus bone graft fusion.

Metallic fusion was used in $84 \%$ of operated patients. Giving the high degree of instability, all cases used bilateral fusion, with 6 screws and 2 rods in $37.5 \%$ of cases and 8 screws with 2 rods in $62.5 \%$ of cases. The metallic implants were also used to apply forces for reduction of fractured segments.

Bone graft fusion was used in $69 \%$ of cases. We evaluated all patients at 2 months after surgery and all cases showed complete consolidation of fractured segments. All cases used bone chips harvested from decompressive osteotomies and excision of mobile bone fragments. In the majority of cases the intervertebral discs were found ruptured. We proceeded with discectomy followed by interbody bone graft fusion. In some cases a posterolateral bone fusion was used. The advantage of bone graft fusion is that it offers long term stability after consolidation. The disadvantage of this method is that patients need at least 3 weeks of bed stay after surgery, increasing the risk of comorbidities associated with immobilization.

To sum it all up, metallic fusion is used to achieve short term stability of the spine and to help in reduction of fractured segments. In our experience, we observed that this type of fusion is not enough for long term stability, as bone tissue suffers a resorption along the course of the screw. For best results in achieving long term stability bone graft fusion is the method to choose, although in comes with some disadvantages.

Fracture reduction was tempted in 16 cases, meaning $84.2 \%$ of operated patients. We managed to achieve reduction of the fractured segments in 14 cases, $73.5 \%$ and reduction was attempted but did not succeed in 2 cases, meaning $10.5 \%$. Reduction was not attempted in 3 cases, $16 \%$ of operated patients for different reasons. The main problem associated with fracture reduction was represented by late timing of surgery which led to a fibrous tissue that made reduction difficult or created adherents with large vessels risking a major bleeding.

\section{Case presentation}

A 24 year old patient, male, that suffered a car accident with a thoracic spine fracture affecting the T8 vertebra with T7-T8 luxation, graded Frankel A, with associated thoracic trauma and a mild traumatic brain injury. The patient was squedueled for surgery 13 days after presentation. We found the dura matter ruptured and complete destruction of the spinal cord. A metallic fusion was used with bilateral transpedicular screws T5, T6, T9 and T10 with 2 rods. We managed to reduce the fracture applying reduction forces on the screws. The T7-T8 disc was found ruptured, followed by T7 discectomy and T7-T8 interbody bone rgaft fusion. The patient was immobilized 6 weeks after surgery. At 2 months follow-up we observed complete consolidation of the interbody fusion. 

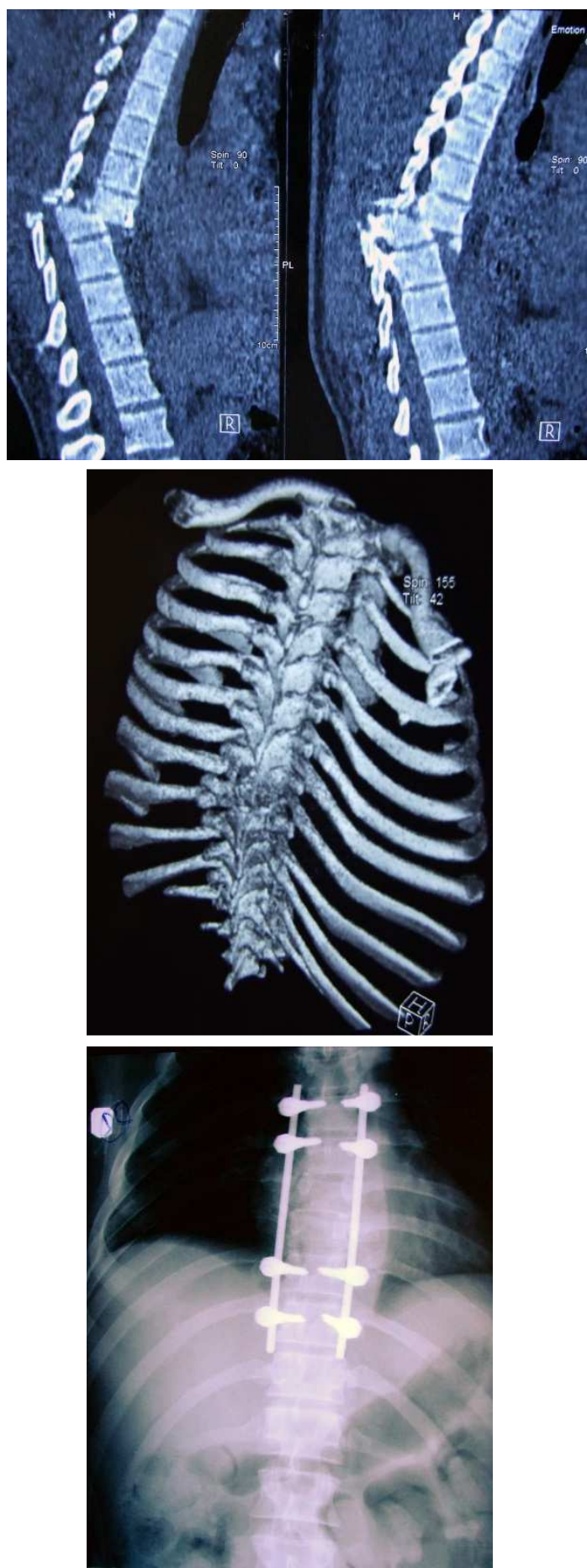

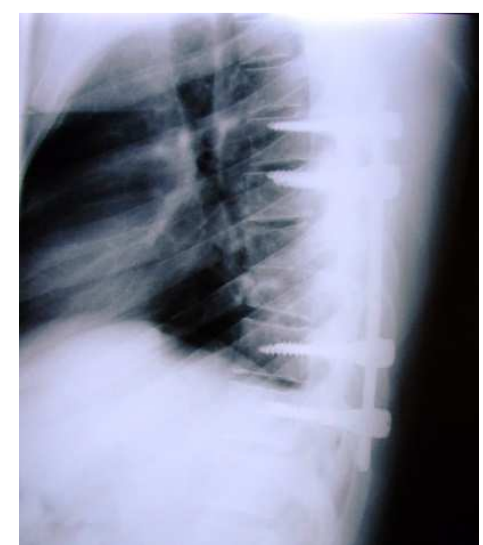

Figure 4 - 24 year old patient with T7-T8 type C fracture before and after surgery

Another 21 year old patient, male, that suffered a car accident, with a type $\mathrm{C}$ thoracic fracture T7-T8, graded Frankel A. Intraoperative, the dura matter was not ruptured and we managed to decompress the spinal cord. A T6-T9 metallic fusion was performed, with 8 transpedicular screws and 2 rods. We managed to reduce the T7-T8 luxation. An intersomatic T7-T8 bone graft fusion was performed. The patient remained Frankel A at 2 months follow-up but had no signs of clinical or radiological instability (Figure 5).

\section{Outcome}

The average hospital stay was 20 days, with a minimum of 3 days and a maximum of 74 days in 4 different admissions. The neurologic status over the course of hospital stay was stationary for 22 patients, $84.5 \%$, all of these patients having a Frankel A grade from admission. 4 patients, meaning $15.5 \%$ of all patients presented improved neurologic status over the course of hospital stay. 

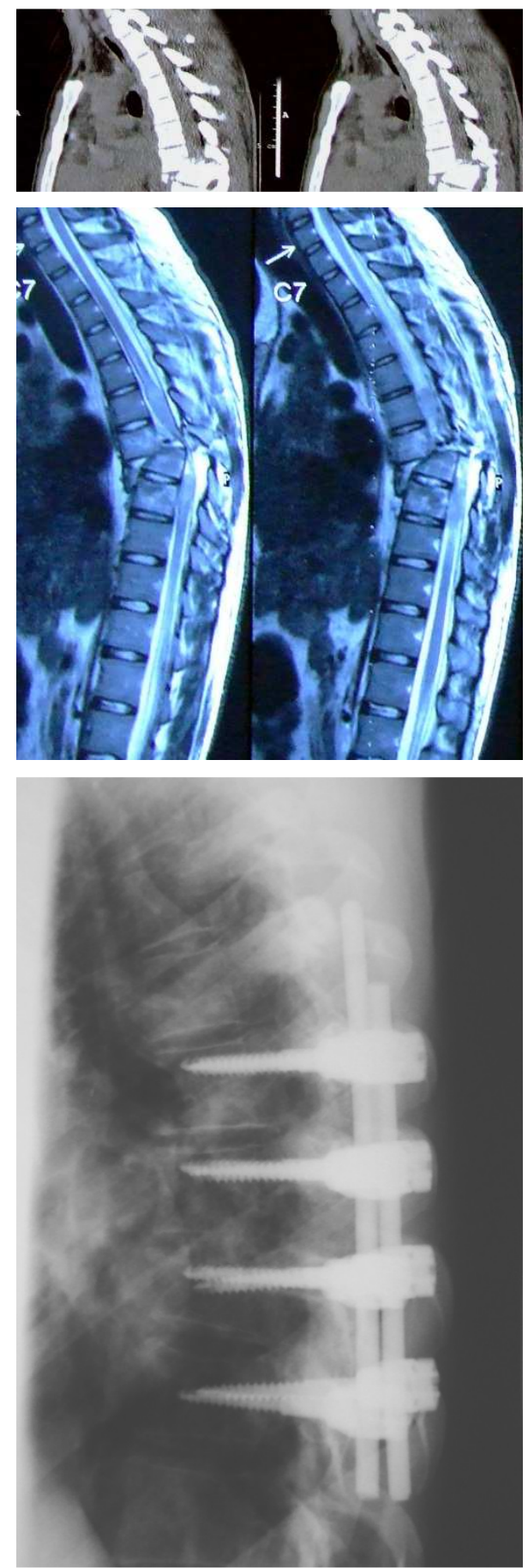

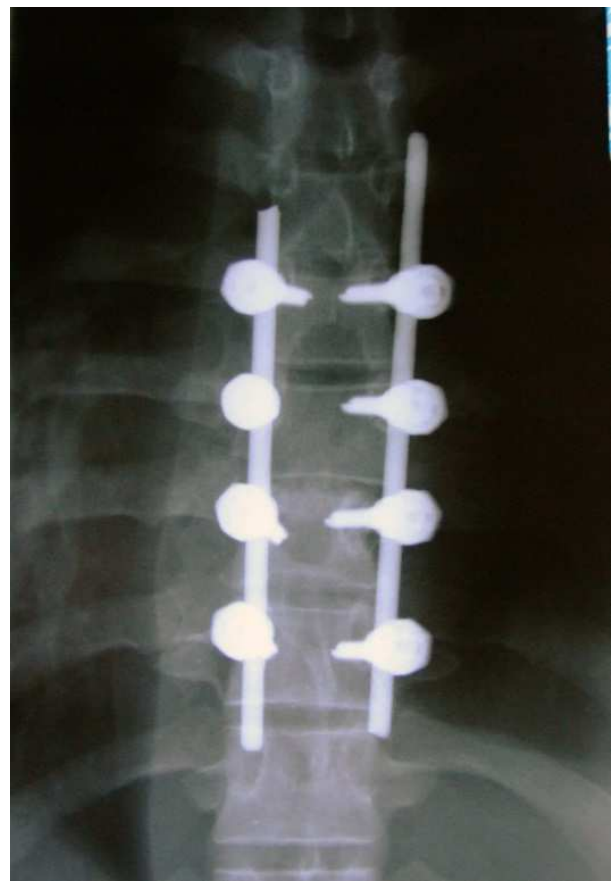

Figure 5 - 21 year old patient with T7-T8 type C fracture before and after surgery

\section{Complications}

The most frequent complications observed in patients with this type of fractures were represented by lesions of the thoracic cage, lungs or myocardium. $50 \%$ of patients associated rib fractures, $92 \%$ of patients haemothorax, $23 \%$ pneumothorax and $11.5 \%$ spleen rupture. Literature studies described a lower incidence of associated lesions in patients with a reduced neurological impairment, only $20 \%$ associating multiple lesions (27).

The most frequent postoperative complications observed in our study were CSF fistula, in 3 cases, patients with worse neurological status in 1 case, pulmonary 
thrombembolism in 1 case and wound hematoma in 1 case.

Late complications included implant failure, observed in 2 cases, superficial wound infection in 2 cases and CSF fistula in one case. CSF fistula represents an important problem for this type of patients, almost half of them presenting dural rupture and CSF leakage during surgical intervention. Dural defect was found in $47 \%$ of operated cases and in $15.8 \%$ of operated cases patients presented radicular dilacerations.

\section{Conclusions}

Type $\mathrm{C}$ thoracic spinal fractures are the most severe lesions of the thoracic spine that occur secondary to high energy accidents and are frequently associated with multiple lesions, pulmonary lesions being the most severe associated complications which dictate the moment of surgery. Patients require a multidisciplinary team approach. The spinal cord is affected in almost $100 \%$ of cases. Surgical intervention through a posterior approach can resolve the main objectives of surgery represented by decompression of the spinal cord and spinal fusion. Autologus bone graft fusion is very important for long term stability of the spine.

\section{References}

1. Harbrecht BG, Djurasovic M: Thoracolumbar spine trauma: diagnostic and therapeutic considerations for the general surgeon. Am Surg 75:191-196, 2009

2. Magerl F, Aebi M, Gertzbein SD, Harms J, Nazarian S (1994) A comprehensive classification of thoracic and lumbar injuries. Eur Spine J 3(4):184-201

3. Operative treatment of 733 patients with acute thoracolumbar spinal injuries: comprehensive results from the second, prospective, internet-based multicenter study of the Spine Study Group of the German Association of Trauma Surgery. M. Reinhold • C. Knop • R. Beisse • L. Audige' • F. Kandziora • A. Pizanis • R. Pranzl • E. Gercek • M. Schultheiss • A. Weckbach • V. Bühren - M. Blauth Received: 11 November 2009 / Revised: 7 March 2010 / Accepted: 9 May 2010 / Published online: 25 May 2010 - Springer-Verlag 2010 4. Schouten R, Ory K, Lee RS, Street JT, Boyd MC, Paquette SJ, et al: Health-related quality-of-life outcomes after thoracic (T1-T10) fractures. Spine J [epub ahead of print], 2013

5. Wood KB, Bohn D, Mehbod A: Anterior versus posterior treatment of stable thoracolumbar burst fractures without neurologic deficit: a prospective, randomized study. J Spinal Disord Tech 18 (Suppl):S15S23, 2005

6. Tator $\mathrm{CH}$ : Review of treatment trials in human spinal cord injury: issues, difficulties, and recommendations. Neurosurgery 59:957-987, 2006

7. Harrop JS, Sharan A, Ratliff J: Central cord injury: pathophysiology, management, and outcomes. Spine J 6 (6 Suppl): 198S-206S, 2006

8. Delamarter RB, Sherman J, Carr JB: Pathophysiology of spinal cord injury. Recovery after immediate and delayed decompression. J Bone Joint Surg Am 77:10421049, 1995

9. Fehlings MG, Tator $\mathrm{CH}$ : An evidence-based review of decompressive surgery in acute spinal cord injury: rationale, indications and timing based on experimental and clinical studies. J Neurosurg 91 (1 Suppl):1-11, 1999 10. Burke DC, Berryman D: The place of closed manipulation in the management of flexion-rotation dislocations of the cervical spine. J Bone Joint Surg Br 53:165-182, 1971

11. Hadley MN, Fitzpatrick BC, Sonntag VK, Browner CM: Facet fracture-dislocation injuries of the cervical spine. Neurosurgery 30:661-666, 1992

12. Vaccaro AR, Daugherty RJ, Sheehan TP, Dante SJ, Cotler JM, Balderston RA, et al: Neurologic outcome of early versus late surgery for cervical spinal cord injury. Spine (Phila Pa 1976) 22:2609-2613, 1997

13. Cengiz SL, Kalkan E, Bayir A, Ilik K, Basefer A: Timing of thoracolomber spine stabilization in trauma patients; impact on neurological outcome and clinical course. A real prospective (rct) randomized controlled study. Arch Orthop TraumaSurg 128:959-966, 2008 
DOI: 10.2478/romneu-2014-0058

14. Carreon LY, Dimar JR: Early versus late stabilization of spine injuries: a systematic review. Spine (Phila Pa 1976) 36:E727-E733, 2011

15. Xing D, Chen Y, Ma JX, Song DH, Wang J, Yang Y, et al: A methodological systematic review of early versus late stabilization of thoracolumbar spine fractures. Eur Spine J 22: 2157-2166, 2013

16. Bellabarba C, Fisher C, Chapman JR, Dettori JR, Norvell DC: Does early fracture fixation of thoracolumbar spine fractures decrease morbidity or mortality? Spine (Phila Pa 1976) 35 (9 Suppl):S138-S145, 2010

17. Croce MA, Bee TK, Pritchard E, Miller PR, Fabian TC: Doesoptimal timing for spine fracture fixation exist? Ann Surg 233:851-858, 2001

18. Delamarter RB, Sherman J, Carr JB: Pathophysiology of spinal cord injury. Recovery after immediate and delayed decompression. J Bone Joint Surg Am 77:10421049, 1995

19. Garfin SR, Blair B, Eismont FJ, Abitol JJ: Thoracic and upper lumbar spine injuries, in Browner BD, Jupiter JB, Levine AM, Neurosurg Focus / Volume 37 / July 2014et al (eds): Skeletal Trauma: Fractures, Dislocations, Ligamentous Injuries, ed 2. Philadelphia: WB Saunders, 1998,Vol 1, pp 947-1034

20. Kerwin AJ, Frykberg ER, Schinco MA, Griffen MM, Arce CA, Nguyen TQ, et al: The effect of early surgical treatment of traumatic spine injuries on patient mortality. J Trauma63:1308-1313, 2007

21. Kerwin AJ, Frykberg ER, Schinco MA, Griffen MM, Murphy T, Tepas JJ: The effect of early spine fixation on non-neurologic outcome. J Trauma 58:15-21, 2005
22. Kerwin AJ, Griffen MM, Tepas JJ III, Schinco MA, Devin T,Frykberg ER: Best practice determination of timing of spinal fracture fixation as defined by analysis of the National Trauma Data Bank. J Trauma 65:824-831, 2008

23. Krengel WF III, Anderson PA, Henley MB: Early stabilization and decompression for incomplete paraplegia due to a thoracic-level spinal cord injury. Spine (Phila Pa 1976) 18: 2080-2087, 1993

24. Schinkel C, Frangen TM, Kmetic A, Andress HJ, Muhr G: Timing of thoracic spine stabilization in trauma patients: impacton clinical course and outcome. J Trauma 61:156-160, 2006

25. Boakye M, Arrigo RT, Hayden Gephart MG, Zygourakis CC, Lad S: Retrospective, propensity scorematched cohort study examining timing of fracture fixation for traumatic thoracolumbar fractures. J Neurotrauma 29:2220-2225, 2012

26. Yurac R, Marre' B, Urzu'a A et al (2006) Residual mobility of instrumented and non-fused segments in thoracolumbar spine fractures. Eur Spine J 15:864-875

27. Thoracic spine fractures: injury profile and outcomes of a surgically treated cohort

Bartolome' Marre' - Vicente Ballesteros - Celmira Martı'nez • Juan J. Zamorano • Francisco Ilabaca • Milan Munjin - Ratko Yurac - Alejandro Urzu'a - Miguel Lecaros - Jose' Fleiderman Received: 21 June 2010 / Revised: 4 December 2010 / Accepted: 11 January 2011 / Published online: 28 January 2011 Springer-Verlag 2011 